\title{
Real-Time Neurofeedback to Modulate $\beta$-Band Power in the Subthalamic Nucleus in Parkinson's Disease Patients
}

\author{
Ryohei Fukuma, ${ }^{1,2^{*}}$ Takufumi Yanagisawa, ${ }^{1,2,3,4,5^{*}}$ Masataka Tanaka, ${ }^{1}$ Fumiaki Yoshida, ${ }^{3,5}$ Koichi \\ Hosomi, ${ }^{1,6}$ Satoru Oshino, ${ }^{1}$ Naoki Tani, ${ }^{1}$ and Haruhiko Kishima ${ }^{1}$
}

https://doi.org/10.1523/ENEURO.0246-18.2018

\begin{abstract}
${ }^{1}$ Department of Neurosurgery, Graduate School of Medicine, Osaka University, Suita, Osaka, 565-0871, Japan,
${ }^{2}$ Department of Neuroinformatics, ATR Computational Neuroscience Laboratories, Seika-cho, Kyoto, 619-0288, Japan, ${ }^{3}$ Institute for Advanced Co-creation Studies, Osaka University, Suita, Osaka, 565-0871, Japan, ${ }^{4}$ Center for Information and Neural Networks (CiNet), National Institute of Information and Communications Technology (NICT), Suita, Osaka, 565-0871, Japan, ${ }^{5}$ JST PRESTO, Suita, Osaka, 565-0871, Japan, and ${ }^{6}$ Department of Neuromodulation and Neurosurgery, Graduate School of Medicine, Osaka University, Suita, Osaka, 565-0871, Japan
\end{abstract}

\begin{abstract}
The $\beta$-band oscillation in the subthalamic nucleus (STN) is a therapeutic target for Parkinson's disease. Previous studies demonstrated that L-DOPA decreases the $\beta$-band $(13-30 \mathrm{~Hz})$ oscillations with improvement of motor symptoms. However, it has not been elucidated whether patients with Parkinson's disease are able to control the $\beta$-band oscillation voluntarily. Here, we hypothesized that neurofeedback training to control the $\beta$-band power in the STN induces plastic changes in the STN of individuals with Parkinson's disease. We recorded the signals from STN deep-brain stimulation electrodes during operations to replace implantable pulse generators in eight human patients ( 3 male) with bilateral electrodes. Four patients were induced to decrease the $\beta$-band power during the feedback training (down-training condition), whereas the other patients were induced to increase (up-training condition). All patients were blinded to their assigned condition. Adjacent contacts that showed the highest $\beta$-band power were selected for the feedback. During the 10 min training, patients were shown a circle whose diameter was controlled by the $\beta$-band power of the selected contacts. Powers in the $\beta$-band during 5 min resting sessions recorded before and after the feedback were compared. In the down-training condition, the $\beta$-band power of the selected contacts decreased significantly after feedback in all four patients $(p<0.05)$. In contrast, the $\beta$-band power significantly increased after feedback in two of four patients in the up-training condition. Overall, the patients could voluntarily control the $\beta$-band power in STN in the instructed direction $(p<0.05)$ through neurofeedback.
\end{abstract}

Key words: beta power; deep brain stimulation; EEG; neurofeedback; Parkinson disease; voluntary control

\section{Significance Statement}

Many studies have reported a relationship between the $\beta$-band power in the subthalamic nucleus (STN) and motor symptoms in Parkinson's disease. Here, we have developed a novel neurofeedback technique using intracranial electrodes implanted in deep brain structures to modulate STN activity. We provided direct feedback of the $\beta$-band power as the size of a black disk to induce a sustainable change in $\beta$-band power. As a result, the neurofeedback training induced significant changes in the $\beta$-band power. This is the first report to demonstrate that human patients with Parkinson's disease were able to voluntarily control their $\beta$-band power in STN to induce changes in the power. 
Table 1 Patients and feedback conditions

\begin{tabular}{|c|c|c|c|c|c|}
\hline Patient ID & Age, y (sex) & Duration of DBS, $y$ & UPDRS-III (On) & \multicolumn{2}{|c|}{ Feedback condition } \\
\hline & & & & & \\
\hline 1 & $53(\mathrm{M})$ & 11 & 27 & Lt $1-2$ & Down-training \\
\hline 2 & 70 (M) & 4 & 29 & Lt $1-2$ & Down-training \\
\hline 3 & $68(\mathrm{~F})$ & 6 & 7 & Lt $1-2$ & Down-training \\
\hline 4 & $52(\mathrm{~F})$ & 5 & 20 & Lt $0-1$ & Down-training \\
\hline 5 & $62(\mathrm{~F})$ & 4 & 26 & Lt $0-1$ & Up-training \\
\hline 6 & $66(\mathrm{M})$ & 9 & 27 & Rt 1-2 & Up-training \\
\hline 7 & $67(\mathrm{~F})$ & 9 & 82 & Rt 1-2 & Up-training \\
\hline 8 & $66(\mathrm{~F})$ & 4 & 31 & Rt 1-2 & Up-training \\
\hline
\end{tabular}

UPDRS-III, Unified Parkinson's Disease Rating Scale Part III; Rt, right; Lt, left.

\section{Introduction}

Parkinson's disease is characterized by abnormal neuronal oscillations in the subthalamic nucleus (STN). Electrophysiological examinations using electrodes for deepbrain stimulation (DBS) have demonstrated that the $\beta$-band oscillations in the STN correlate with the symptoms of Parkinson's disease (Little and Brown, 2012; Pavlides et al., 2015). In addition, treatment with dopaminergic (L-DOPA) medication improves Parkinson's disease symptoms, such as bradykinesia and rigidity, while simultaneously attenuating $\beta$-band power (Brown et al., 2001; Cassidy et al., 2002; Priori et al., 2004; Kühn et al., 2006a; Weinberger et al., 2006; Hammond et al., 2007; Ray et al., 2008). Similarly, DBS in the STN suppresses $\beta$-band oscillation (Eusebio et al., 2011). Moreover, recent studies have demonstrated that an adaptive DBS using $\beta$-band oscillation improved Parkinson's disease symptoms better than the continuous use of DBS. These improvements were correlated with the attenuation of $\beta$-band oscillations (Little et al., 2013; Tinkhauser et al., $2017)$, so $\beta$-band oscillation in the STN may be a therapeutic target for clinical interventions such as rehabilitation.

However, it has not been revealed whether patients with Parkinson's disease voluntarily modulate the $\beta$-band oscillation in the STN for rehabilitation. Because the $\beta$-band oscillation in the STN is a part of the cortico-basal

Received June 19, 2018; accepted November 28, 2018; First published , 20. The authors declare no competing financial interests.

Author contributions: R.F., T.Y., M.T., F.Y., K.H., S.O., N.T., and H.K. performed research; R.F. analyzed data; R.F. and T.Y. wrote the paper; T.Y. designed research.

This work was supported by the Brain/MINDS by AMED, and in part by SRPBS by MEXT and AMED; JST PRESTO (JPMJPR1506 and JPMJPR178C), CREST(JPMJCR18A5) and ERATO(JPMJER1801); Grants-in-Aid for Scientific Research from KAKENHI (JP24700419, JP26560467, JP22700435, JP15H05710, and JP16K10787); SICP from AMED; TERUMO Foundation for Life Sciences and Arts; and the Japan Foundation of Aging and Health. We thank the patients for their participation in this study.

${ }^{*}$ R.F. and T.Y. contributed equally to this work.

Correspondence should be addressed to Takufumi Yanagisawa, Osaka University, 2-2 Yamadaoka, Suita, Osaka 565-0871, Japan. E-mail: tyanagisawa@nsurg.med.osaka-u.ac.jp.

https://doi.org/10.1523/ENEURO.0246-18.2018

Copyright (C) 2018 Fukuma et al.

This is an open-access article distributed under the terms of the Creative Commons Attribution 4.0 International license, which permits unrestricted use, distribution and reproduction in any medium provided that the original work is properly attributed. ganglia-thalamocortical network, it is affected by various voluntary activities such as motor intentions (Blumenfeld and Brontë-Stewart, 2015). Previous studies have demonstrated coherent oscillations, including $\beta$-band throughout the network, such as STN and internal globus pallidus (GPi; Brown et al., 2001), GPi and cortex (Williams et al., 2002), STN and thalamus (Hanson et al., 2012), and STN and cortex (Litvak et al., 2011; Whitmer et al., 2012; de Hemptinne et al., 2013). It has also been reported that not only actual hand movement but also mental imagery to move the hand changes the $\beta$-band power in the STN of patients with Parkinson's disease (Kühn et al., 2006b), which is affected by the cortical activations linked to the basal ganglia (Raffin et al., 2012; Blumenfeld and BrontëStewart, 2015). Voluntary modulation of $\beta$-band oscillation in the STN might, therefore, induce some plastic changes in activities.

Neurofeedback has been demonstrated to induce plastic changes in various cortical activities (Emmert et al., 2016), including those in Parkinson's disease (Beuter et al., 2014). Studies using real-time monitoring of cortical activities demonstrated that neurofeedback could induce changes in cortical activity and function (Ganguly et al., 2011; Wander et al., 2013; Orsborn et al., 2014). For some patients after strokes, neurofeedback with magnetoencephalography and electroencephalography successfully modulated the $\alpha$ or $\beta$ power of the cortical current such that the patients' symptoms improved (Buch et al., 2008; Ramos-Murguialday et al., 2013; Chaudhary et al., 2015). Hence, the $\beta$-band oscillation in the STN of patients with Parkinson's disease might be modulated through the neurofeedback training. Here, we hypothesized that patients with Parkinson's disease could control the intensity of the $\beta$-band oscillation of the STN using real-time feedback of the STN recordings. Moreover, the motor symptoms of the patients were evaluated by electromyograms (EMGs) of their upper limbs to examine the relationship with the $\beta$-band oscillation of the STN.

\section{Materials and Methods}

\section{Patients}

Eight patients with bilateral STN-DBS electrodes (3 males and 5 females) were recruited in the Neurosurgery Department of Osaka University Hospital at a location which will be identified if the article is published (Table 1; for DBS parameter settings, see Table 2). The ethics 
Table 2. DBS parameter settings

\begin{tabular}{|c|c|c|c|c|}
\hline Patient ID & Contacts & Frequency, $\mathrm{Hz}$ & Pulse width, $\mu \mathrm{S}$ & Voltage \\
\hline 1 & Lt $1-2-C+$ & 130 & 60 & 3.4 \\
\hline Rt $2-3-C+$ & 60 & 3.5 & & \\
\hline 2 & Lt $2-3-C+$ & 130 & 90 & 3.0 \\
\hline Rt $2-3-C+$ & 90 & 2.4 & & \\
\hline 3 & Lt $2-C+$ & 60 & 60 & 3.9 \\
\hline Rt $0-C+$ & 90 & 3.8 & & \\
\hline 4 & Lt $0-1-C+$ & 60 & 90 & 3.2 \\
\hline Rt $0-\mathrm{C}+$ & 90 & 3.2 & & \\
\hline 5 & Lt $1-\mathrm{C}+$ & 60 & 90 & 4.1 \\
\hline Rt $1-\mathrm{C}+$ & 90 & 4.1 & & \\
\hline 6 & Lt $2-3-C+$ & 125 & 60 & 2.7 \\
\hline Rt $2-\mathrm{C}+$ & 90 & 2.6 & & \\
\hline 7 & Lt $2-C+$ & 60 & 90 & 3.9 \\
\hline Rt $2-\mathrm{C}+$ & 90 & 4.0 & & \\
\hline 8 & Lt $2-3-C+$ & 140 & 60 & 3.2 \\
\hline Rt $1-2-3-C+$ & 130 & 90 & 2.8 & \\
\hline
\end{tabular}

Rt, Right; Lt, left.

committee of Osaka University Hospital approved this study (no. 14448), and it was performed in accordance with approved protocols. All patients gave written informed consent to participate before the experiment.

\section{Signal measurement}

During operations with local anesthesia for replacement of implantable pulse generators, signals from bilateral DBS electrodes were measured at $10 \mathrm{kHz}$ by electroencephalograph (EEG; NIHON KOHDEN). The DBS electrode was $1.27 \mathrm{~mm}$ in diameter and had four contacts on its tip in the axial direction (Model 3389, Medtronic). Each contact was $1.5 \mathrm{~mm}$ long, and the spacing between contacts was $0.5 \mathrm{~mm}$. EMG from the flexor digitorum superficialis and the extensor digitorum communis of each hand were also measured at the same time to evaluate symptoms. These muscles were selected as the antagonistic muscle pairs that were accessible even during the operation.

\section{Experimental design}

The experiment was performed with patients lying on the surgical bed and 2-3 h after medication was administered. Each patient participated in three sessions in the following order: pre-feedback session, feedback session, and post-feedback session. In the $5 \mathrm{~min}$ pre- and postfeedback sessions, the patients were instructed to close their eyes and not to fall asleep. During the $10 \mathrm{~min}$ feedback session, patients were instructed to make the radius of a black circle on a computer screen smaller by using their thoughts somehow, without moving their bodies (Fig. 1). The computer screen was fixed in front of the patient's face, $\sim 20-40 \mathrm{~cm}$ away, so that the patient could comfortably see the black circle, which had a maximum radius of $\sim 10 \mathrm{~cm}$. Movements of the body were visually monitored; in addition, those of the hands were also monitored using EMG. The radius of the circle was controlled by $\beta$-band power scaled in the range of $0-1$, in two directions (for the scaling method, see Real-time feedback). For four patients in the down-training group, the radius was proportional to the normalized power so that the scaled power of 0 showed no black circle, and that of 1 gave the maximum radius of the circle. In contrast, for the other four patients in the up-training group, the radius was negatively correlated to the scaled power to give the maximum radius with the value of 0 .

\section{Real-time feedback}

During the pre-feedback and feedback sessions, $\beta$-band power was calculated in real-time using a script running on MATLAB (MathWorks). Measured signals were first transferred from EEG to MATLAB via TCP/IP. At 50 ms intervals, the last $500 \mathrm{~ms}$ bipolar signals from adjacent contacts were applied with a Hamming window and fast Fourier transformation to obtain the power spectrum. The power spectrum within the $\beta$-band was averaged, and the square root was calculated to find the $\beta$-band power. In this series of procedures, only functions built into MATLAB, or supplied in MathWorks toolboxes were used to calculate power. Adjacent contacts that showed the highest

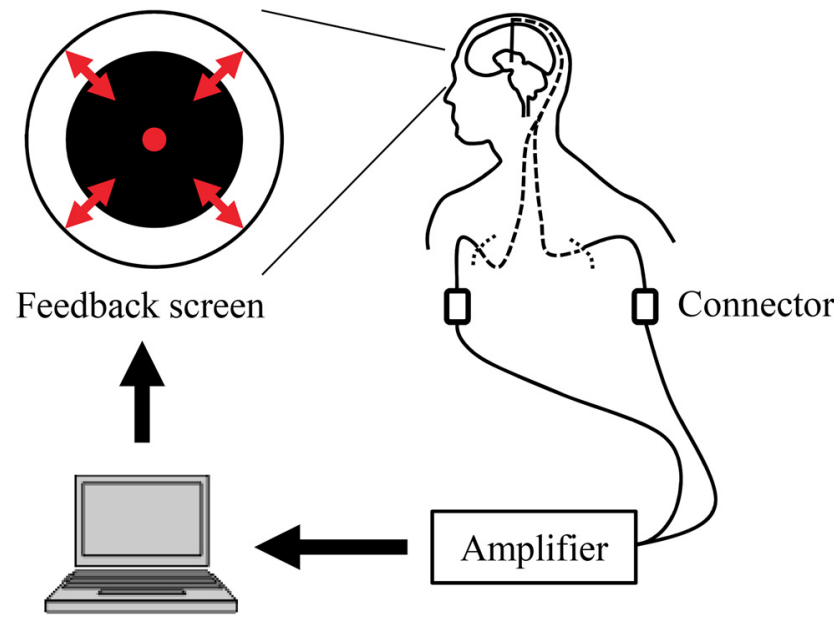

Figure 1. Feedback system overview. Signals from the DBS electrodes were acquired in real time. The radius of the black circle on the computer screen was controlled based on the $\beta$-band power of the acquired bipolar signals from adjacent contacts that were selected in the pre-feedback session. 
Pre-feedback session

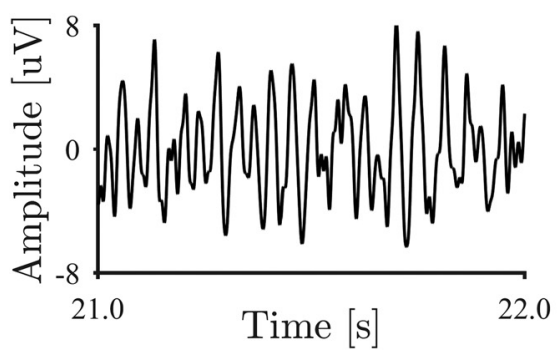

Feedback session

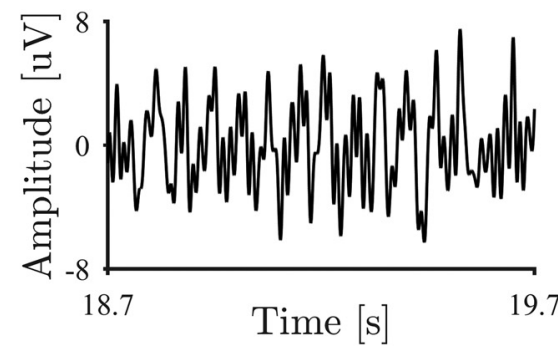

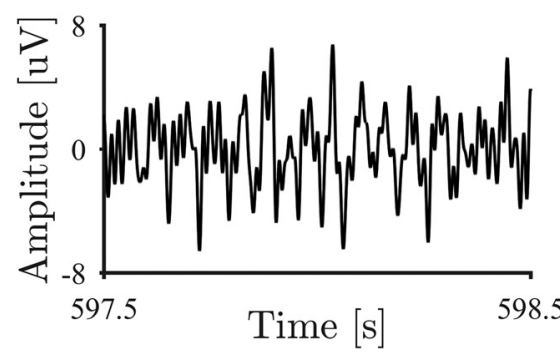

Figure 2. Representative DBS signals. DBS signals of Patient 2 during pre-feedback session, and at the beginning and the ending of feedback session were shown. For higher readability, the signals were bandpass filtered between 4 and $80 \mathrm{~Hz}$.

$\beta$-band (13-30 Hz) power during the pre-feedback session were selected for the contacts to control the circle during the subsequent feedback session. During the feedback session, the $\beta$-band power of the selected adjacent contacts, calculated in real-time, was scaled into a range of $0-1$ to control the radius of the feedback circle. The scaling was performed so that lower limit (0) and upper limit (1) of the range corresponded to the minimum and maximum power, respectively, of the same contacts during the pre-feedback session. If the scaled power exceeded the range of $0-1$, the scaled power was clipped within the range so that the maximum and minimum radius of the circle was limited. The radius of the feedback circle was sent via serial port to another computer, on which the feedback circle was displayed using in-house custom software.

\section{Signal processing}

To evaluate the changes induced by the feedback training, the $\beta$-band power of the $10 \mathrm{kHz}$ sampled DBS signals was calculated from the signals recorded during the preand post-feedback sessions. At first, noisy portions of the recordings were discarded based on visual inspection before further analysis, and the clean signals were divided into non-overlapping $1 \mathrm{~s}$ time windows. For each time window, the DBS signals from the selected contacts for the feedback training were applied with a Hamming window and fast Fourier transformation to obtain a power spectrum. The $\beta$-band power of each time window was obtained as the square root of the averaged spectrum between 13 and $30 \mathrm{~Hz}$.

The power of the EMG signals measured from the forearm contralateral to the selected DBS contacts was also calculated to evaluate the effect of feedback training on the symptoms. The EMG signals were processed in the same manner as the DBS signals, except the power spectra were averaged between 4 and $10 \mathrm{~Hz}$ from the flexor digitorum superficialis and the extensor digitorum communis to calculate the EMG power.

The $\beta$-band power of the DBS signals from the selected contacts, and the EMG power from the contralateral forearm were also calculated using the recording during the feedback training. Calculations of both powers were performed in the same manner as in that of the rest sessions, except the signals during the feedback task were divided into 600 non-overlapping $1 \mathrm{~s}$ time windows.

\section{Statistics}

The $\beta$-band power of the selected DBS contacts was compared between the pre- and post-feedback sessions to evaluate the effect of feedback training. For each patient, the $\beta$-band powers of the $1 \mathrm{~s}$ time windows during the two rest sessions were compared with a one-tailed unpaired $t$ test to evaluate whether each patient successfully induced changes in the $\beta$-band powers in the instructed direction. Moreover, to test whether the patients could control the $\beta$-band power according to the instructions as a group, the difference of the averaged $\beta$-band power during the two rest sessions was evaluated. For the down-training group, the difference was calculated as the power of pre-feedback session subtracted from that of post-feedback session (post - pre); for the up-training group, the power of the post-feedback session was subtracted from that of pre-feedback session (pre - post). By applying one-sample $t$ test to the differences, the $t$ value was calculated; a one-tailed permutation test was performed to examine the significance of the $t$ value by comparing it with a distribution of the $t$ values expected by chance. The chance distribution was obtained by randomly shuffling the powers of the two rest sessions for the same patient before taking their average, 10,000 times. The effect of the feedback training on the symptoms was also evaluated in the same manner as the $\beta$-band power using the EMG powers, which were calculated from the EMG signals of the flexor digitorum superficialis and the extensor digitorum communis, and within the frequency range of $4-10 \mathrm{~Hz}$.

The relationship between the EMG power and the $\beta$-band power during feedback training was evaluated using Pearson's correlation coefficient. For each patient, the correlation coefficient between the EMG and $\beta$-band power was calculated. Correlation coefficients expected by chance were also calculated by randomly shuffling the order of the power within each patient. The true and chance correlation coefficients were Fisher $z$-transformed and tested using a two-tailed unpaired $t$ test.

\section{Results}

The signals from the DBS electrodes implanted in the patients demonstrated characteristic $\beta$-band signals during the resting state. Figure 2 shows an example of the signals before the feedback training, and $\beta$-band oscillation was shown in the example. The power spectra of the 
Pt. 1 (Down-training)

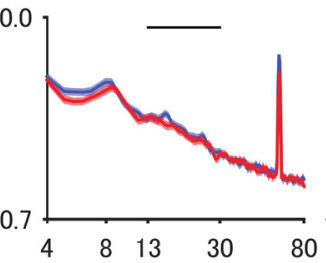

Pt. 5 (Up-training)
Pt. 2 (Down-training)
Pt. 3 (Down-training)
Pt. 4

(Down-training)
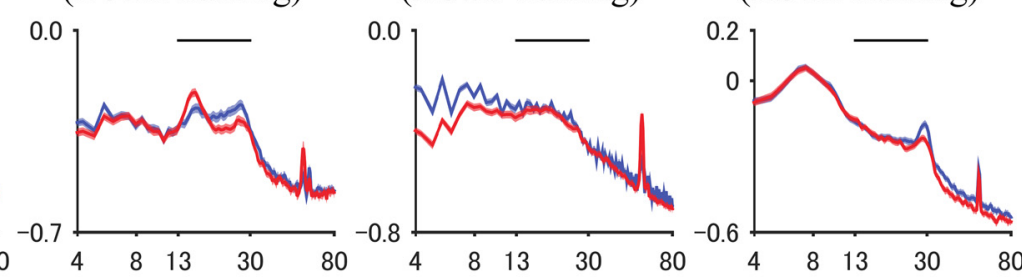

Pt. 7

(Up-training)

Pt. 8

Pt. 6

(Up-training)
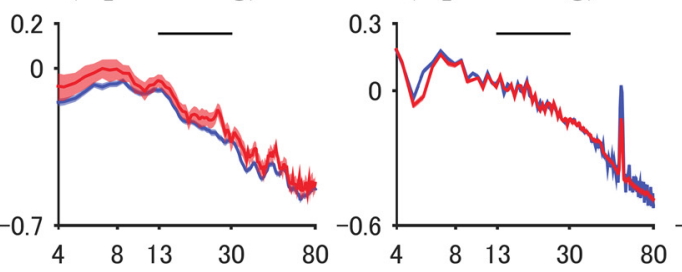

(Up-training)

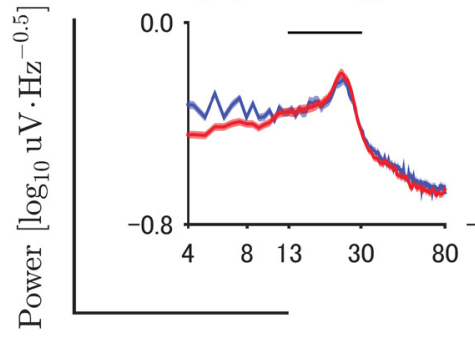

Frequency $[\mathrm{Hz}]$

Pre - Post

Figure 3. Power spectra during pre- and post-feedback sessions. Blue and red lines denote the power spectrum of DBS signals during resting state before and after the feedback training, respectively. Shaded areas represent the estimated $95 \%$ confidence interval of the power spectrum among $1 \mathrm{~s}$ time windows. The horizontal line above the data curves shows the range of $\beta$-band used for feedback training. Frequency is shown on a log scale.

DBS electrodes were evaluated during the resting states before and after the feedback training. After the first recording of the resting state, we selected the pair of adjacent DBS contacts showing the greatest $\beta$-band power during the resting state for each patient (Table 1). The power spectra from these contacts showed peaks around the $\beta$ band (13-30 Hz), as shown in Figure 3.

The neurofeedback training induced changes in the $\beta$-band power of the selected DBS contacts. The representative example of the signals demonstrated that the characteristic frequency and the amplitude changed during the neurofeedback training (Fig. 2). Figure 3 shows that the $\beta$-band power of the selected DBS contacts changed after the feedback training. For all patient except Patients 5 and 7 , the $\beta$-band power was significantly changed in the targeted direction after the 10 min feedback, during which the radius of the black circle was controlled in proportion or in inverse proportion to the normalized $\beta$-band power in the STN evaluated online $(p$
$<0.05$, one-tailed unpaired $t$ test; Table 3, a). Notably, for all patients in down-training group, the $\beta$-band power was significantly decreased after the training, whereas only two of four patients in the up-training group showed a significant increase in the $\beta$-band power. On the whole, the $\beta$-band power was significantly changed in the targeted directions after the feedback training (Fig. $4 ; p=$ 0.009 , one-tailed permutation test; Table 3, b). The powers in other frequency bands (such as $\theta, \alpha$, low $\gamma$ ) did not, however, change significantly before and after the neurofeedback training (Fig. 5).

We recorded the EMG signals of the forearm contralateral to the selected contacts during the resting state. For Patients 1, 2, and 3, the power spectrum of the EMG demonstrated peaks between 4 and $10 \mathrm{~Hz}$, which corresponded to the tremor (Fig. 6). Although the $\beta$-band power changed significantly in the targeted direction, the EMG power between 4 and $10 \mathrm{~Hz}$ measured from the contralateral hand to the selected contacts did not

Table 3. Statistical table

\begin{tabular}{|c|c|c|c|}
\hline & Data structure & Type of test & Statistics \\
\hline a & Normal distribution & One-tailed unpaired $t$ test & $\begin{array}{l}\text { Patient 1: } t_{(598)}=3.286, p<0.001 \\
\text { Patient 2: } t_{(598)}=2.762, p=0.003 \\
\text { Patient 3: } t_{(598)}=3.013, p=0.001 \\
\text { Patient 4: } t_{(598)}=4.644, p<0.001 \\
\text { Patient 5: } t_{(598)}=-1.241, p=0.108 \\
\text { Patient 6: } t_{(338)}=-3.852, p<0.001 \\
\text { Patient 7: } t_{(598)}=0.743, p=0.771 \\
\text { Patient 8: } t_{(598)}=-1.763, p=0.039\end{array}$ \\
\hline b & No assumption & One-tailed permutation test & $p=0.009$ \\
\hline C & No assumption & Two-tailed permutation test & $p=0.627$ \\
\hline d & Approximate normal distribution & Two-tailed unpaired $t$-test & $t_{(14)}=0.749, p=0.466$ \\
\hline
\end{tabular}




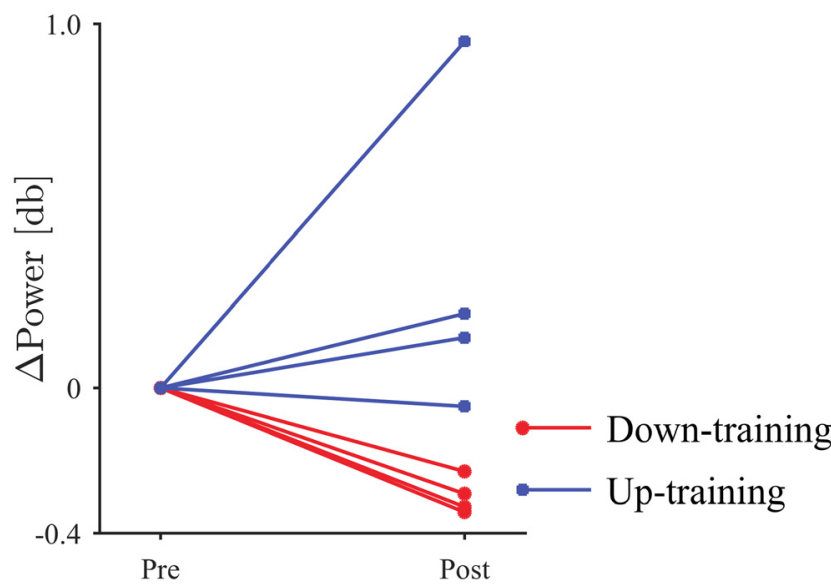

Figure 4. The difference in $\beta$-band power between the pre- and post-feedback sessions. The circular markers and red lines denote the down-training condition, whereas the square markers and blue lines indicate the up-training condition.

change consistently after feedback $(p=0.627$, two-tailed permutation test; Table 3, c; for EMG change of each patient; Fig. 6).

According to the patients' reports after feedback training (Table 4), some patients tried to control the radius of the feedback circle through strategies relating to movement intentions. However, we observed no apparent movements or EMG activity caused by movements during the feedback training, and there were no consistent relationships between the $\beta$-band power and the EMG power during the training $(p=0.466$, two-tailed unpaired $t$ test; Table 3, d).

\section{Discussion}

The $\beta$-band power of STN was demonstrated to be voluntarily modulated through feedback training by patients with Parkinson's disease. Moreover, the induction of the alteration in the $\beta$-band power of STN was not significantly correlated to the motor intention during the training and the EMG power during the resting states.

It should be noted that the $\beta$-band power was successfully decreased for all patients in the down-training group and for two of four patients in the up-training group. The patients with Parkinson's disease may have had difficulty increasing the $\beta$-band power during the resting state because the $\beta$-band power was already high because of the pathophysiology of the disease.

Although the $\beta$-band power during resting state was successfully changed by the feedback training, the patients' symptoms, especially tremor, had no apparent change. The 10 min feedback training might not be long enough to induce symptomatic alterations. Long-term effects of neurofeedback are expected with more frequent and longer feedback training using the adaptive DBS system that can transmit signals wirelessly. It might also be possible that the $\beta$-band power does not cause the tremor symptoms directly. Recent studies suggested that the phase-amplitude coupling between $\beta$-phase and high- $\gamma$ amplitude in the primary motor cortex causes the characteristic tremor of Parkinson's disease rather than the simple $\beta$-band power (de Hemptinne et al., 2013, 2015). Neurofeedback training using the phase-amplitude coupling might improve this symptom. Neurofeedback training with online evaluation of the abnormal oscillation may be used to demonstrate the pathophysiological relationship between the abnormal oscillation and symptoms.

In our experiments, we instructed patients to control the circle without moving their bodies. Patients were unaware that the circle was related to the STN activities that are modulated by movement. However, one patient reported that he tried a strategy relating to limb movement. It is possible that patients involuntarily thought about movements during training, but failed to report these thoughts
Theta $(4-8 \mathrm{~Hz})$

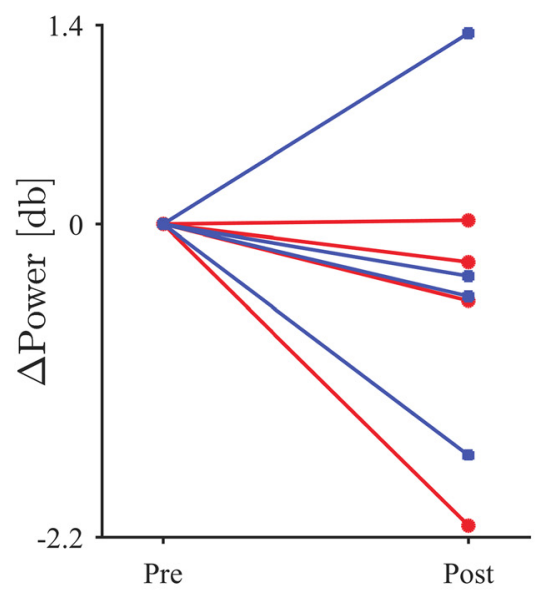

Alpha $(8-13 \mathrm{~Hz})$

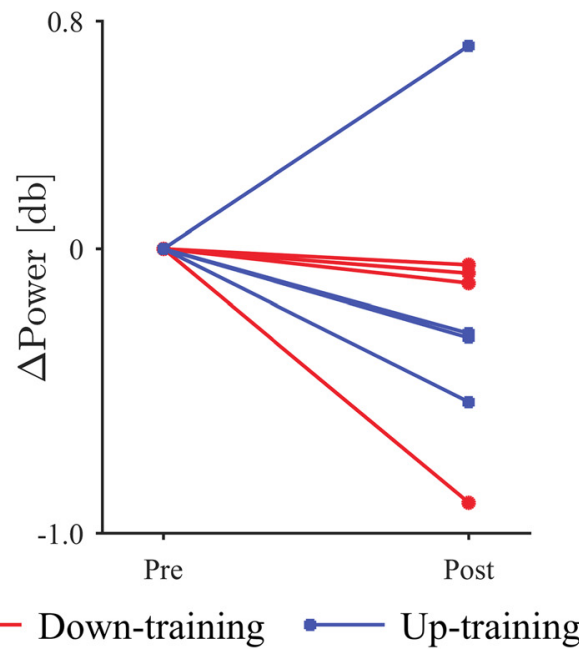

Low- $\gamma(30-50 \mathrm{~Hz})$

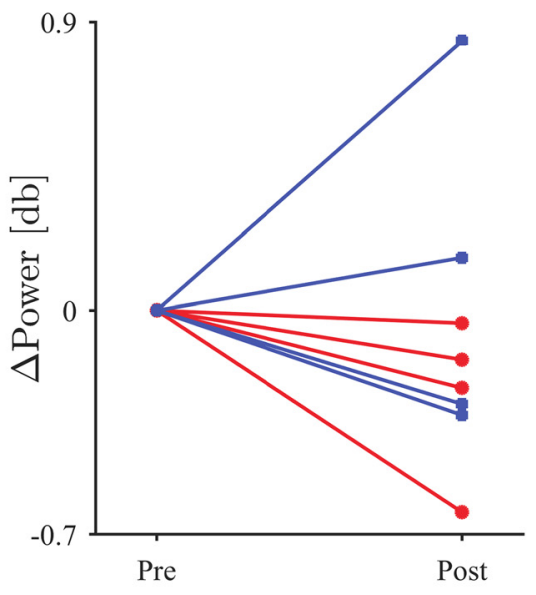

Figure 5. Comparison of powers between the pre- and post-feedback sessions. In common frequency bands other than $\beta$-band, difference of powers between two sessions was shown. The circular markers and red lines denote the down-training condition, whereas the square markers and blue lines indicate the up-training condition. 
Pt. $2(-0.34 \mathrm{db})$

Down-training

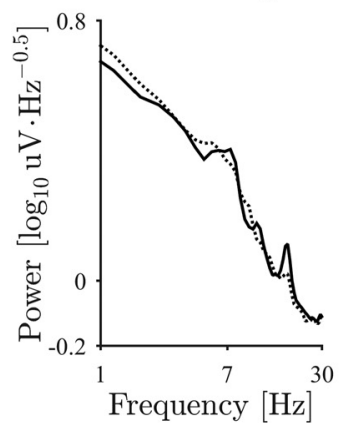

Pt. 7 (-0.05 db)

Up-training

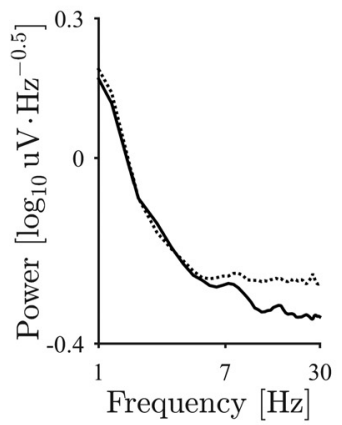

Pt. 4 (-0.33 db)

Down-training

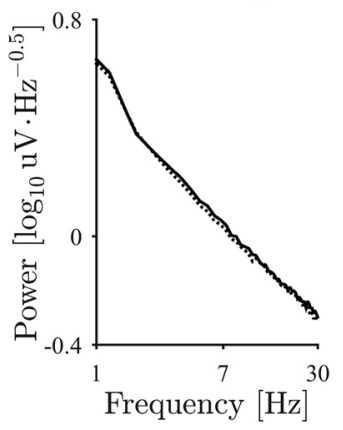

Pt. $8(+0.14 \mathrm{db})$ Up-training

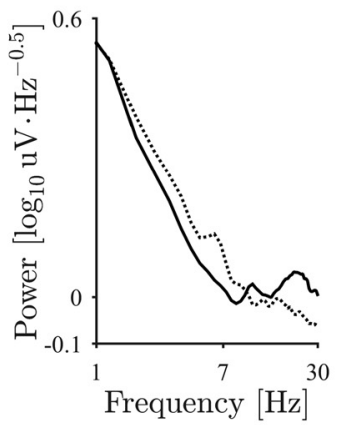

Pt. 3 (-0.29 db)

Down-training

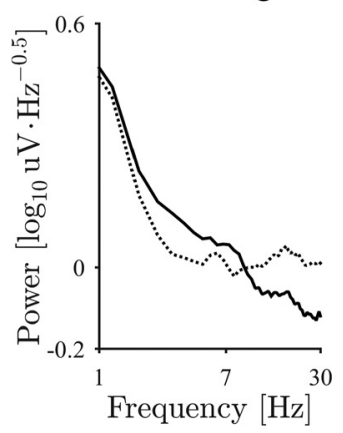

Pt. $5(+0.20 \mathrm{db})$ Up-training

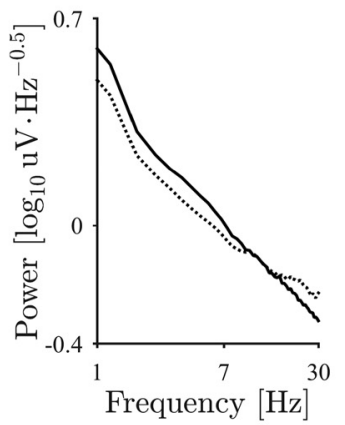

Pt. 1 (-0.23 db)

Down-training

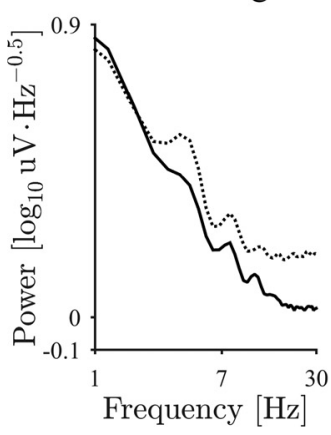

Pt. $6(+0.95 \mathrm{db})$ Up-training

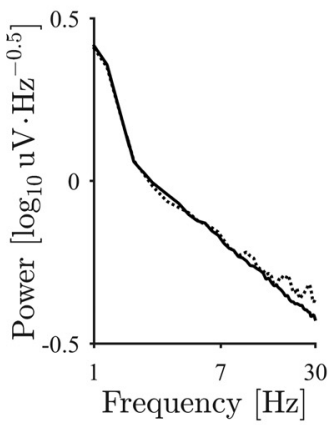

Figure 6. Power spectra of EMG during the pre- and post-feedback sessions. Solid and dashed lines denote the power spectra during resting state before and after the feedback training, respectively. Frequency is shown on a log scale. Each plot shows the patient ID in the title and the difference of $\beta$-band power at the selected DBS contacts in the post-feedback session compared to the pre-feedback session. The plots are ordered from left to right, then top panels to bottom panels, so that the differences of $\beta$-band power are sorted in ascending order.

afterward (either because they forgot or they simply wished to conform to the instructions not to move the body). However, we did not observe any apparent movement during the feedback training, nor did we see a consistent correlation between $\beta$-band power in STN and forearm EMG power. Thus, the data indicate that explicit motor intention had little effect on controlling the feedback circle in this training, and our results demonstrate that the neurofeedback system was able to induce a significant alteration in the $\beta$-band power during a resting state regardless of the explicit movement intentions.

\section{Conclusion}

Our feedback training successfully demonstrated that the $\beta$-band power of the STN could be modulated to increase or decrease based on the patients' voluntary

Table 4. Patients' reports about feedback training

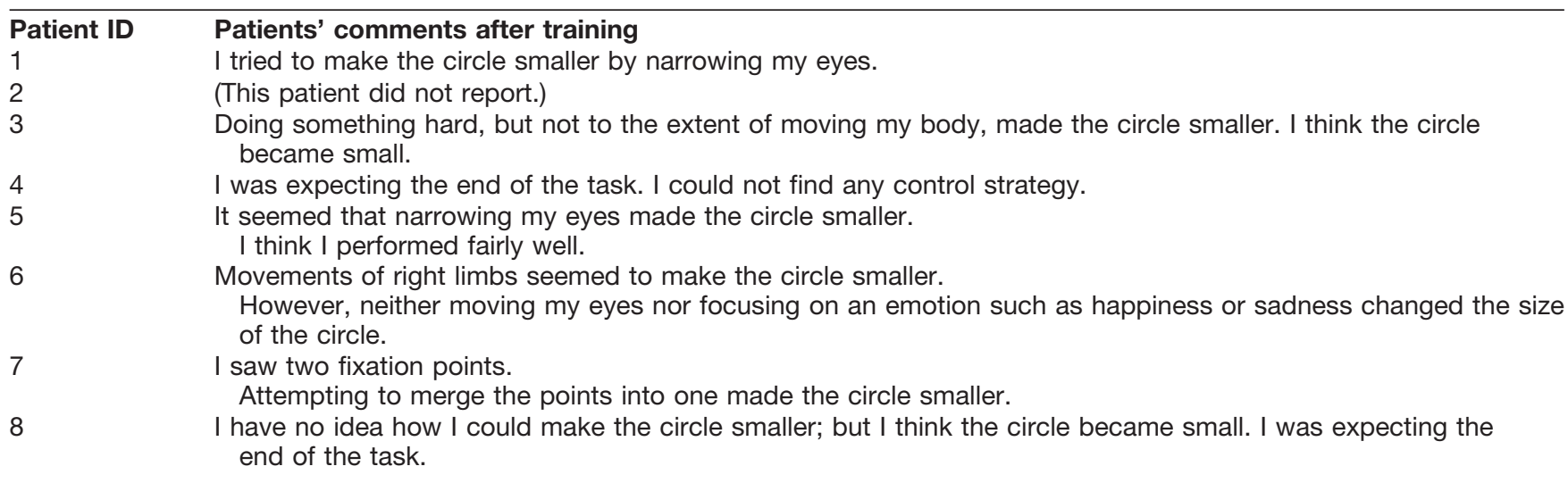


control. The neurofeedback training may be an effective method for revealing the pathophysiological role of the abnormal oscillations and for developing a novel treatment for Parkinson's disease.

\section{References}

Beuter A, Lefaucheur JP, Modolo J (2014) Closed-loop cortical neuromodulation in Parkinson's disease: An alternative to deep brain stimulation? Clin Neurophysiol 125:874-885. CrossRef Medline

Blumenfeld Z, Brontë-Stewart H (2015) High frequency deep brain stimulation and neural rhythms in Parkinson's disease. Neuropsychol Rev 25:384-397. CrossRef Medline

Brown P, Oliviero A, Mazzone P, Insola A, Tonali P, Di Lazzaro V (2001) Dopamine dependency of oscillations between subthalamic nucleus and pallidum in Parkinson's disease. J Neurosci 21:10331038. Medline

Buch E, Weber C, Cohen LG, Braun C, Dimyan MA, Ard T, Mellinger J, Caria A, Soekadar S, Fourkas A, Birbaumer N (2008) Think to move: a neuromagnetic brain-computer interface $(\mathrm{BCl})$ system for chronic stroke. Stroke 39:910-917. CrossRef

Cassidy M, Mazzone P, Oliviero A, Insola A, Tonali P, Di Lazzaro V, Brown P (2002) Movement-related changes in synchronization in the human basal ganglia. Brain 125:1235-1246. Medline

Chaudhary U, Birbaumer N, Curado MR (2015) Brain-Machine Interface (BMI) in paralysis. Ann Phys Rehabil Med 58:9-13. CrossRef Medline

de Hemptinne C, Swann NC, Ostrem JL, Ryapolova-Webb ES, San Luciano M, Galifianakis NB, Starr PA (2015) Therapeutic deep brain stimulation reduces cortical phase-amplitude coupling in Parkinson's disease. Nat Neurosci 18:779-786. CrossRef Medline de Hemptinne C, Ryapolova-Webb ES, Air EL, Garcia PA, Miller KJ, Ojemann JG, Ostrem JL, Galifianakis NB, Starr PA (2013) Exaggerated phase-amplitude coupling in the primary motor cortex in Parkinson disease. Proc Natl Acad Sci U S A 110:4780-4785. CrossRef Medline

Emmert K, Kopel R, Sulzer J, Brühl AB, Berman BD, Linden DE, Horovitz SG, Breimhorst M, Caria A, Frank S, Johnston S, Long Z, Paret C, Robineau F, Veit R, Bartsch A, Beckmann CF, Van De Ville D, Haller S (2016) Meta-analysis of real-time fMRI neurofeedback studies using individual participant data: How is brain regulation mediated? Neurolmage 124:806-812. CrossRef

Eusebio A, Thevathasan W, Doyle Gaynor L, Pogosyan A, Bye E, Foltynie T, Zrinzo L, Ashkan K, Aziz T, Brown P (2011) Deep brain stimulation can suppress pathological synchronisation in parkinsonian patients. J Neurol Neurosurg Psychiatry 82:569-573. CrossRef Medline

Ganguly K, Dimitrov DF, Wallis JD, Carmena JM (2011) Reversible large-scale modification of cortical networks during neuroprosthetic control. Nat Neurosci 14:662-667. CrossRef Medline

Hammond C, Bergman H, Brown P (2007) Pathological synchronization in Parkinson's disease: networks, models and treatments. Trends Neurosci 30:357-364. CrossRef Medline

Hanson TL, Fuller AM, Lebedev MA, Turner DA, Nicolelis MA (2012) Subcortical neuronal ensembles: an analysis of motor task association, tremor, oscillations, and synchrony in human patients. J Neurosci 32:8620-8632. CrossRef Medline

Kühn AA, Kupsch A, Schneider GH, Brown P (2006a) Reduction in subthalamic 8-35 Hz oscillatory activity correlates with clinical improvement in Parkinson's disease. Eur J Neurosci 23:19561960. CrossRef
Kühn AA, Doyle L, Pogosyan A, Yarrow K, Kupsch A, Schneider GH, Hariz MI, Trottenberg T, Brown P (2006b) Modulation of beta oscillations in the subthalamic area during motor imagery in Parkinson's disease. Brain 129:695-706. CrossRef

Little S, Brown P (2012) What brain signals are suitable for feedback control of deep brain stimulation in Parkinson's disease?. Ann N Y Acad Sci 1265:9-24. CrossRef Medline

Little S, Pogosyan A, Neal S, Zavala B, Zrinzo L, Hariz M, Foltynie T, Limousin P, Ashkan K, FitzGerald J, Green AL, Aziz TZ, Brown P (2013) Adaptive deep brain stimulation in advanced Parkinson disease. Ann Neurol 74:449-457. CrossRef Medline

Litvak V, Jha A, Eusebio A, Oostenveld R, Foltynie T, Limousin P, Zrinzo L, Hariz MI, Friston K, Brown P (2011) Resting oscillatory cortico-subthalamic connectivity in patients with Parkinson's disease. Brain 134:359-374. CrossRef Medline

Orsborn AL, Moorman HG, Overduin SA, Shanechi MM, Dimitrov DF, Carmena JM (2014) Closed-loop decoder adaptation shapes neural plasticity for skillful neuroprosthetic control. Neuron 82:13801393. CrossRef Medline

Pavlides A, Hogan SJ, Bogacz R (2015) Computational models describing possible mechanisms for generation of excessive beta oscillations in Parkinson's disease. PLoS Comput Biol 11: e1004609. CrossRef Medline

Priori A, Foffani G, Pesenti A, Tamma F, Bianchi AM, Pellegrini M, Locatelli M, Moxon KA, Villani RM (2004) Rhythm-specific pharmacological modulation of subthalamic activity in Parkinson's disease. Exp Neurol 189:369-379. CrossRef Medline

Raffin E, Mattout J, Reilly KT, Giraux P (2012) Disentangling motor execution from motor imagery with the phantom limb. Brain 135: 582-595. CrossRef Medline

Ramos-Murguialday A, Broetz D, Rea M, Läer L, Yilmaz O, Brasil FL, Liberati G, Curado MR, Garcia-Cossio E, Vyziotis A, Cho W, Agostini M, Soares E, Soekadar S, Caria A, Cohen LG, Birbaumer N (2013) Brain-machine-interface in chronic stroke rehabilitation: A controlled study. Ann Neurol 74:100-108. CrossRef Medline

Ray NJ, Jenkinson N, Wang S, Holland P, Brittain JS, Joint C, Stein JF, Aziz T (2008) Local field potential beta activity in the subthalamic nucleus of patients with Parkinson's disease is associated with improvements in bradykinesia after dopamine and deep brain stimulation. Exp Neurol 213:108-113. CrossRef Medline

Tinkhauser G, Pogosyan A, Little S, Beudel M, Herz DM, Tan H, Brown P (2017) The modulatory effect of adaptive deep brain stimulation on beta bursts in Parkinson's disease. Brain 140:10531067. CrossRef Medline

Wander JD, Blakely T, Miller KJ, Weaver KE, Johnson LA, Olson JD, Fetz EE, Rao RP, Ojemann JG (2013) Distributed cortical adaptation during learning of a brain-computer interface task. Proc Natl Acad Sci U S A 110:10818-10823. CrossRef Medline

Weinberger M, Mahant N, Hutchison WD, Lozano AM, Moro E, Hodaie M, Lang AE, Dostrovsky JO (2006) Beta oscillatory activity in the subthalamic nucleus and its relation to dopaminergic response in Parkinson's disease. J Neurophysiol 96:3248-3256. CrossRef Medline

Whitmer D, de Solages C, Hill B, Yu H, Henderson JM, BronteStewart $\mathrm{H}$ (2012) High frequency deep brain stimulation attenuates subthalamic and cortical rhythms in Parkinson's disease. Front Hum Neurosci 6:155. CrossRef Medline

Williams D, Tijssen M, Van Bruggen G, Bosch A, Insola A, Di Lazzaro V, Mazzone P, Oliviero A, Quartarone A, Speelman H, Brown P (2002) Dopamine-dependent changes in the functional connectivity between basal ganglia and cerebral cortex in humans. Brain 125:1558-1569. Medline 